\title{
Importance of International Education for International Cooperation - Activities and Contributions of the International Space University -
}

\author{
By Yoshiki MORINO and Walter PEETERS \\ International Space University, Illkirch-Graffenstaden, France
}

(Received July 14th, 2009)

\begin{abstract}
The International Space University (ISU) has been conducting unique space education for more than twenty years and has been contributing to the realization of efficient international cooperation in a broad space arena. Recently, new trends of major space activities are emerging such as back to the moon exploration and global environmental preservation, which are particularly requesting international cooperation in many ways. This paper presents current educational activities at this very unique university, and analyzes how ISU can contribute to promote international cooperation in these important space activities, particularly focusing on relationship to Japan.
\end{abstract}

Key Words: Space Education, International Cooperation, International Space University, ISU

\section{Introduction}

International cooperation is getting more and more important for revitalizing and further expanding world space activities $^{1)}$. In a long-term view, education would be the most crucial aspect to improve and promote international cooperation. The International Space University (ISU) has been conducting this kind of education for more than twenty years and is contributing to the realization of efficient international cooperation in the space arena ${ }^{2)}$. Recently, new trends of major space activities are emerging such as back to the moon exploration and global environmental preservation, which are particularly requesting international cooperation in many ways. On the other hand personnel resources to support this trend do not seem to be enough at present, particularly in Japan $^{3)}$. This paper presents current educational activities at this very unique university, and analyzes how ISU can contribute to promote international cooperation in these important space activities.

\section{Evolution of ISU}

In 1988, three young space enthusiasts took initiative of starting the Summer Session Program (SSP) at Massachusetts Institute of Technology supported by many important space personalities and major space agencies. This program was characterized by its 3I concept, that is, International, Intercultural and Interdisciplinary, which are essential elements to promote and vitalize space activities worldwide. Students and lecturers came from all over the world, interacting with each other and advancing their interdisciplinary thinking. The location of the SSP has been changing every year, covering five continents and continuing to rotate at present. Recently SSP has been redefined as Space Studies Program so as to be accommodated in the southern hemisphere.
In parallel with the SSP, a one year master program was conceived to expand the benefit of this 3I concept and realized as MSS, Masters in Space Study in 1997 using the facility of Strasbourg University. A dedicated university building was completed in 2002 in Illkirch-Graffenstaden, suburbs of Strasbourg city. From 2004 onwards, a master in space management course was added and the ISU master course is from then onward designated as MSS/MSM. Here MSM stands for "Masters in Space Management". In addition to these main programs, two programs are offered intended towards executive education. This year a new program, called Executive MBA (Master of Business Administration) has been started to educate senior management personnel in space industry. Besides, annual symposium is held at the ISU main campus to promote in depth understanding on various important space issues. Fig. 1 shows the evolution of ISU educational activity in hours by student number for all programs. The activity level was nearly doubled by the introduction of master courses and is regularly increasing still.

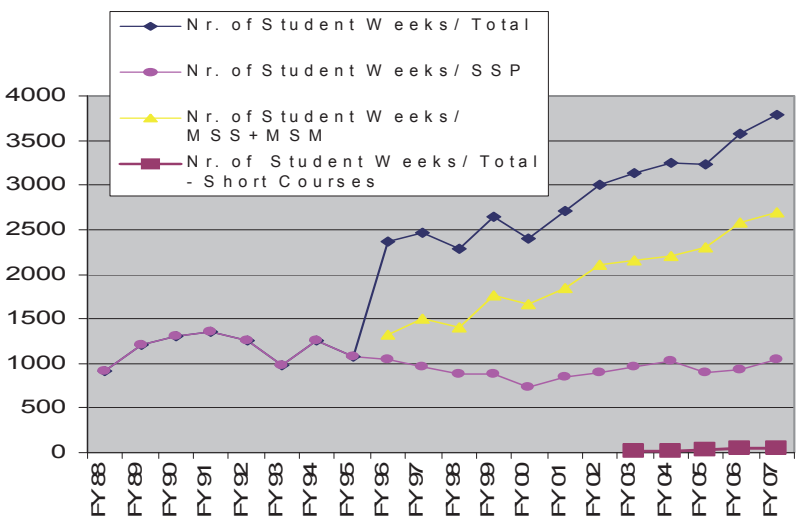

Fig. 1. Evolution of student weeks. 


\section{Unique Features of the ISU Curriculum}

In this chapter, ISU's main activities and their unique features are described in detail.

\subsection{SSP}

The SSP is held from late June to late August. The number of students varies from 100 to 130 from all over the world. Lecturers are experts in various space fields, belonging to universities, industries and space agencies from all over the world as well. Site locations are changing year by year and covered five continents as shown in Fig. 2. Strasbourg main campus hosts an SSP session every three or four years. In 2009, this year, SSP is held at NASA Ames Research Center, California, USA and in 2010 it is scheduled to come back to Strasbourg in cooperation with Stuttgart University. A typical SSP curriculum is shown in Fig. 3.

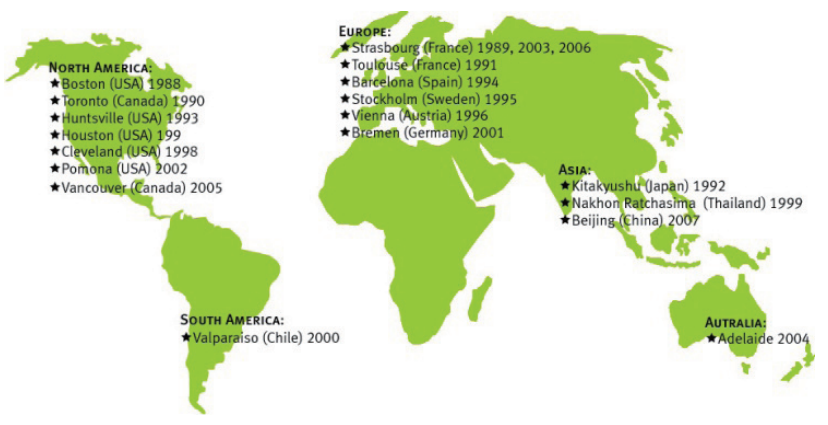

Fig. 2. Past SSP locations all over the world.

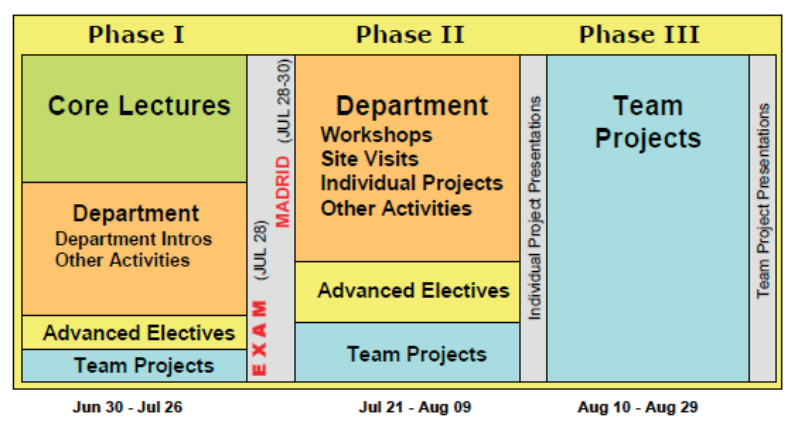

Fig. 3. Typical SSP curriculum.

The official language of all SSP programs is English and a good level of English capabilities are required, though complementary English language courses are provided before the start of the program.

The SSP consists of three phases. The first phase mainly consists of so called core lectures, which cover broad area of space disciplines such as science, technology, economics, policy and law. Examples of the lectures are,

- Launch Sites and Space Ports

- Policy Rationales for Space Activities

- Cost Estimation and Risk Management

The second phase is characterized by the departmental activities. SSP students belong to one of departments based on their preferred disciplines and attend elective workshops and seminars. Examples of such activities are as follows.

- Space Industry: Mid-term goals, opportunities and challenges

- International Astronaut Panel: The next 20 years of human space flight - goals and milestones

- Lunar Exploration: Overlaps, competition, cooperation, and the way forward

The phase three is dedicated mostly to Team Projects supported and guided by TP chairs with expertise in the subject. SSP students choose one of the two or three themes proposed and form a Team to tackle the project, cooperating with each others and finally producing a high quality report. The TP themes in 2008 Barcelona were as follows.

- TP Volcano ('VAPOR'): Use of Space Technologies for Monitoring Volcano Hazards

- TP Spaceports ('FuturIST'): The Necessary Infrastructure for a Private Spaceflight

- TP Lunar X-Prize ('Noumenia'): Return to the Moon in a New Way

Along with the activities described above, various events take place such as theme days which are held and attended by external experts as panelists. Examples of these are as follows.

- Space Industry: Mid-term goals, opportunities and challenges

- The Way Forward for Europe in Space

- International Astronaut Panel: The next 20 years of human space flight - goals and milestones

- Lunar Exploration : Overlaps, competition, cooperation, and the way forward

Through these lectures, workshops, Team Projects and various events, SSP students can absorb a broad knowledge in up-to-date space activities and get practical skills to work in international and interdisciplinary environments. Moreover, by closely interacting with various cultures and different backgrounds, the participants can be better prepared to enter future international projects in their own working environments afterwards. ISU's international network will also support their future activities all over the world, independent from (political) borders.

\subsection{MSS/MSM}

MSS/MSM program is one year master course (for post-graduate students) starting from September 1, at ISU's main campus in Illkirch-Graffenstaden which located near Strasbourg, France.

The number of students varies each year around 50-60, coming from all over the world similar to the SSP program. Typically, a class of this size will represent $25+$ different nationalities. At present 8 faculty in various background are resident at the main campus and many others are visiting lecturers from all over the world. The overall staff of ISU, headed by the President, is approximately 30 persons. 


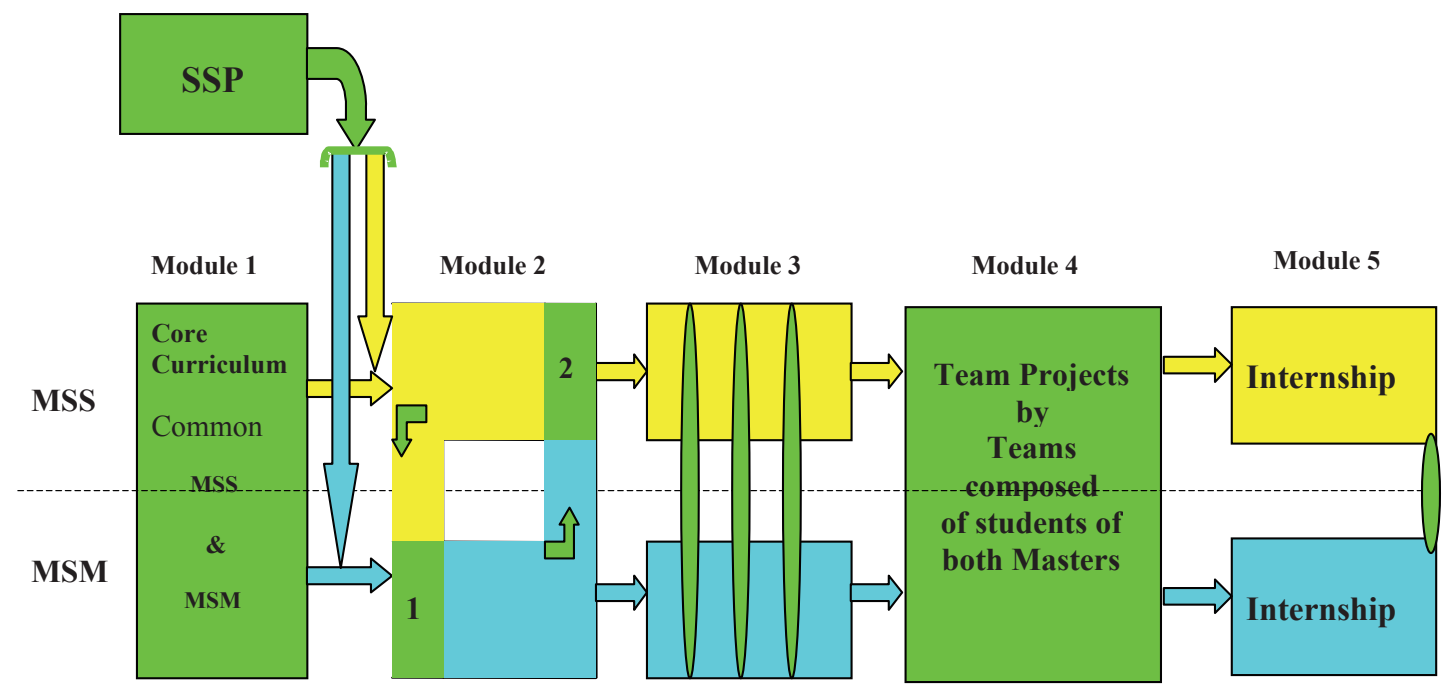

Fig. 4. Typical MSS/MSM curriculum.

One academic year schedule is shown in Fig. 4. It consists of five modules. Students are required to select one of two streams from Module 2 onwards. The MSS course is for science and technology oriented students and MSM course is for management oriented students. During Module 1, all students take same lectures called the core curriculum, which gives basic knowledge on broad space technologies and activities. From a very early stage of the Module 1, team assignments are provided to foster friendship and team work skills among the students. These kinds of small assignments are frequently given through Module 3 and help student to get prepared for the final Team Projects. Examples of these assignments are as follows.

- Analysis of the political and legal issues for space activities in emerging nations

- Space Mission Preliminary Design

- Request for Proposals (RFP)

At the end of Module 1, professional visits to major aerospace companies are planned to get accustomed to real industry activities. Several other visits are scheduled through Module 4. Examples of companies visited are as follows.

- SES Astra (satellite operator)

- EADS (large satellite manufacturer)

- SNECMA (propulsion systems)

- MeteoFrance (meteorological services)

From Module 1 to 3 onwards, several theme day events are planned. Experts in the topic area are invited and panel discussions are conducted with participation of the students. These theme days include

-Space and Security

-Space and Disaster Management

- Living and Working in Space

- Business of Remote Sensing

From Module 2, SSP graduate students (who are regarded as equivalent to having finished Module 1) join the course. Some of the Module 2 lectures are still common to both course but other more disciplinary lectures are devoted to only MSS or MSM. In this module, students have to select one of the two given TP themes and conduct a literature survey on each theme (this is called Team project part 1). Report submission and presentation is imposed at the end of the module. The given themes presented in 2009 were as follows.

- Space Solutions for Climate Change (selected by 26 students)

- Space and Security (selected by 22 students)

The scope of the given theme is very broad and each team has to narrow dawn their focal area during the literature survey or afterwards that in order to produce high quality original final report in Module 4. It is important to find important unsolved gaps in the existing literatures to set the goal to produce useful results. During the team project work, support from the faculty is minimal and most of the project management including team organization and schedule is left to students' autonomous decision.

In Module 3, personal assignment is due to each student, who select one of the themes given by Faculty or he can propose his own theme. The result must be written in a report and presented in a group of students. Recently concurrent design facility (shown in Fig. 5) is introduced and utilized in workshops given in Module 2. This facility is also used in personal assignments and team projects.

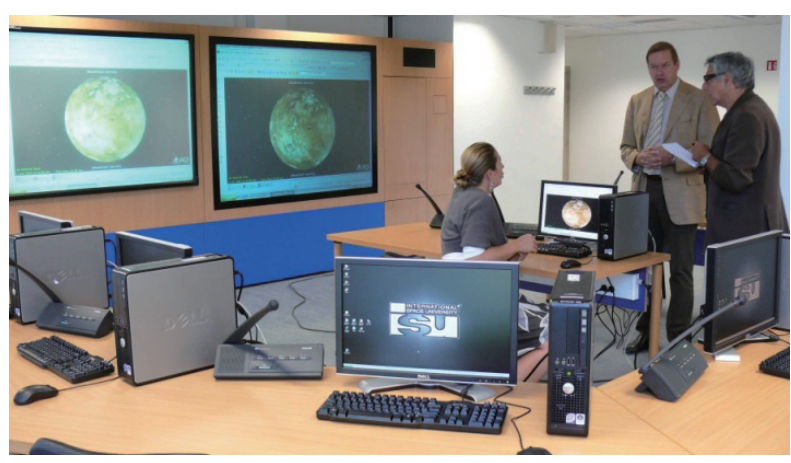

Fig. 5. Concurrent design facility at ISU MSS/MSM.

In addition, communication with small satellites on orbit has become possible using the ground facility newly installed 
in the ISU building as shown in Fig. 6. This helps the students to feel real time space activities in the class room.
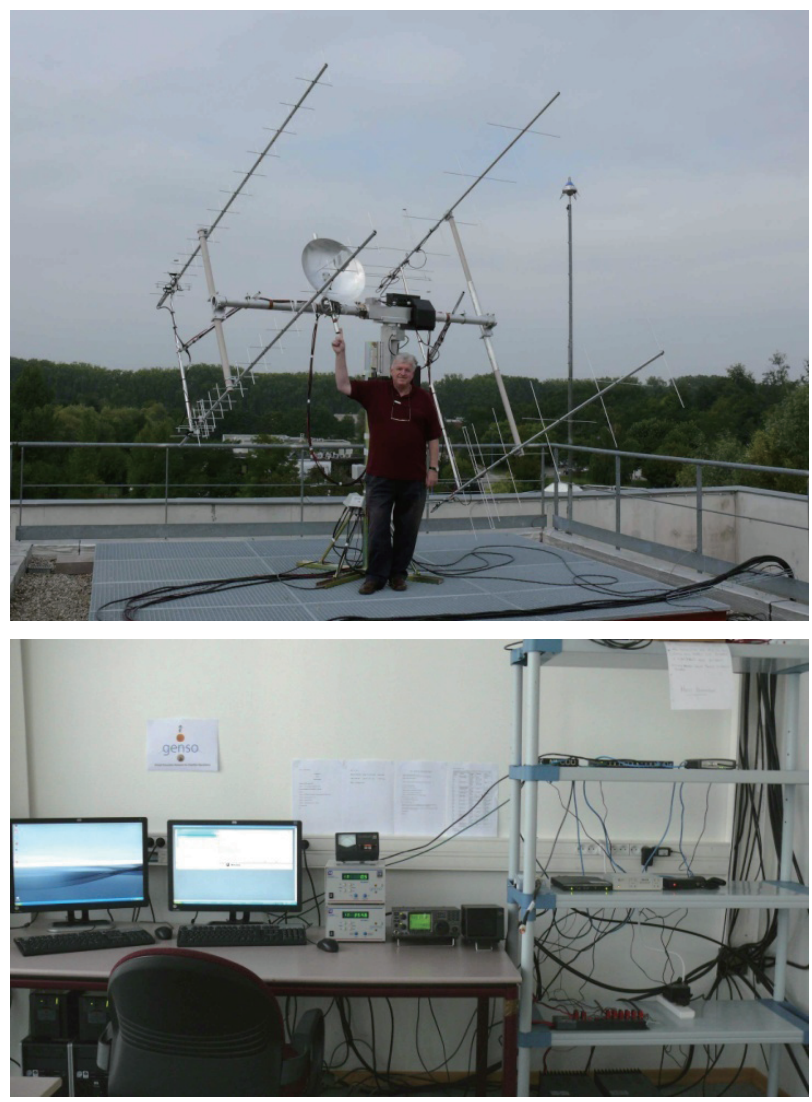

Fig. 6. Ground station for small satellites at ISU.

There are few tasks on Team Project in Module 3 but the team must submit LOI (Letter of Intent) to clarify their focused area and procedure of their project in Module 4. Annual ISU symposium is held in late Module 3 and students are requested to attend and actively participate in the symposium, from which Module 3 exam questions are likely to be taken. The themes of the previous years symposia are as follows.

2007: Why the Moon?

2008: Space Solutions to Earth's Global Challenges

2009: Space for a Safe and Secure World

Many distinguished space experts are participating this symposium and very important and typical discussions among them are very much stimulating the students in many ways. In the case of 2009 symposium, its theme was very relevant to the themes of the Team Project, thus very helpful in view of focusing the project through discussion with the various experts.

Module 4 is totally devoted to the team project. More than 20 members of each team work together taking their responsible tasks distributed by themselves. The final title of the report reflects their specific topic and is usually different from the beginning in Module 2 as a more specific focus is made. In addition to writing a report, they have to make high quality presentation in the main conference room while the event is broadcast via internet all over the world. Final titles of previous years are as follows.

2007:

1) Full Moon: Storage and delivery of oxygen and hydrogen for lunar exploration

2) START: Space Tools supporting Archaeological Research and Tasks

2008:

1) ALERTS: Analysis of lunar exploratory robotic tasks for safety

2) Great expectations: an assessment of the potential for suborbital transportation

2009:

1) Climate Links

2) Space and Responsive Systems

After the graduation, participants of each team often presented their results at major international space events like IAC and COPUOS. By working together for several months to achieve such final report, all members of the team establish strong friendship which will last many years after graduation.

The last Module 5 is devoted to internship starting late May to mid August. All the students go out to companies, universities and space agencies all over the world and experience on the job training of space activities. From Module 2 onwards, students begin to search for their possible host institution based on their preferable field of work, supported by ISU administration and faculty. Some of the regular host institutions are as follows.

- NASA Centers, JPL

- ESA, DLR, EADS, SES

- JAXA, Tohoku University

Students are requested to write a report guided by the internship mentor at the host institute and make a presentation just before their graduation.

\subsection{Short programs}

ISU provide short courses, in particular the Executive Space Course (ESC) $)^{4)}$.

This one-week program is targeted towards middle to higher management space professionals in the space sector, often working in non-technical areas (legal, finance, international affairs, outreach...). The aim of the course is primarily to make them familiar with space technology and applications, allowing them to better understand the implications thereof in their daily activities.

Other short development programs are organized ad-hoc in coordination with the requesting organization.

\subsection{Executive MBA}

This program has newly started this year (2009) focusing on space financing and business ${ }^{4}$. It is highly recommended to middle level managers at space industries and agencies to improve management skills and getting better prepared to international cooperation and competition. The program is divided into six modules of which five require residential participation. In order to enhance the international character, 
locations vary as shown on the following schedule (Fig. 7). The modules are linked to each other but can be interrupted for specific circumstances if necessary and resumed with a subsequent class. With prior approval of the Dean of ISU permission may be granted to take modules out of the scheduled sequence. As with other ISU programs, all modules must be completed within 7 years. The program starts in June and comes to completion in December of the following year. Each of the first four modules has a specific topic which will be covered in depth, and, as such, each module could be selected separately. At the end of each residential module a test will be taken and the successful candidates will receive a certificate.

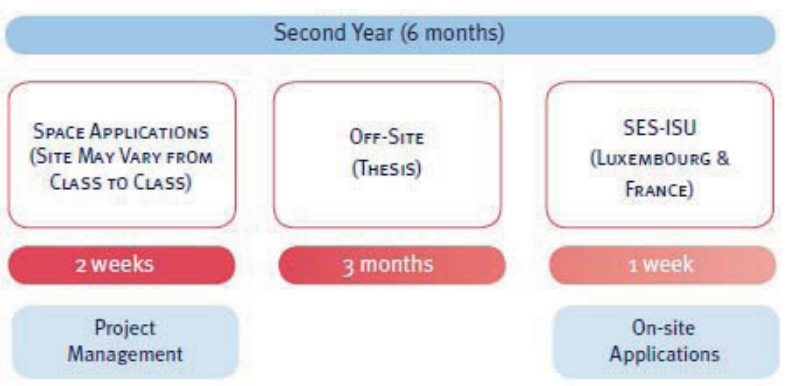

Fig. 7. Executive MBA curriculum.

\section{International Cooperation and Education}

\subsection{Increasing importance of international cooperation}

Although space development activities started in severe competition between the two super space powers during 1950s, international cooperation became more and more important as the cold war era was ending. This process was accelerated by the diversification of utilization and apparent budget limitation for the high cost large projects. Development of international cooperation can be associated with symbolic events such as:

- Apollo-Soyuz Docking:

- European Launcher development:

- Formation of ESA

- International Space Station Program (ISS)

Now, following the completion of the ISS and retirement of the Space Shuttle, the international space world is facing another challenge on how to cooperate in the big issues such as,

- Space exploration back to the moon and toward mars

- Global Climate Change

In the field of space commercialization, space markets have been considerably expanded and diversified, international cooperation and competition became the key issue for the success of the business. Examples of this category are,

- Space communication networks

- Commercial launchers

- Global navigation system

- Commercial Earth observation

- Small Satellites business
Another trend is the increasing number of participating countries in space activities, not only new space powers, such as China and India, but many other emerging countries in Asia and Africa. Obviously it will become more and more complex to manage and cope with competition and cooperation involving these new emerging players.

\subsection{ISU education and international cooperation}

In order to work in such a complex space business environments, following expertise or skills are very helpful.

- Language conversation (English + alpha)

- Negotiation skill

- Team work and management

- Interdisciplinary knowledge

- Comprehension of different cultures.

This also became evident from an extensive survey made by ISU in a large number of space entities, where it became evident from the comments of HR managers that many of these soft skills are hindering recruitment ${ }^{5}$. Fig. 8 illustrates the response of this survey, expressed in terms of number of respondents qualifying the respective skills in order of importance.

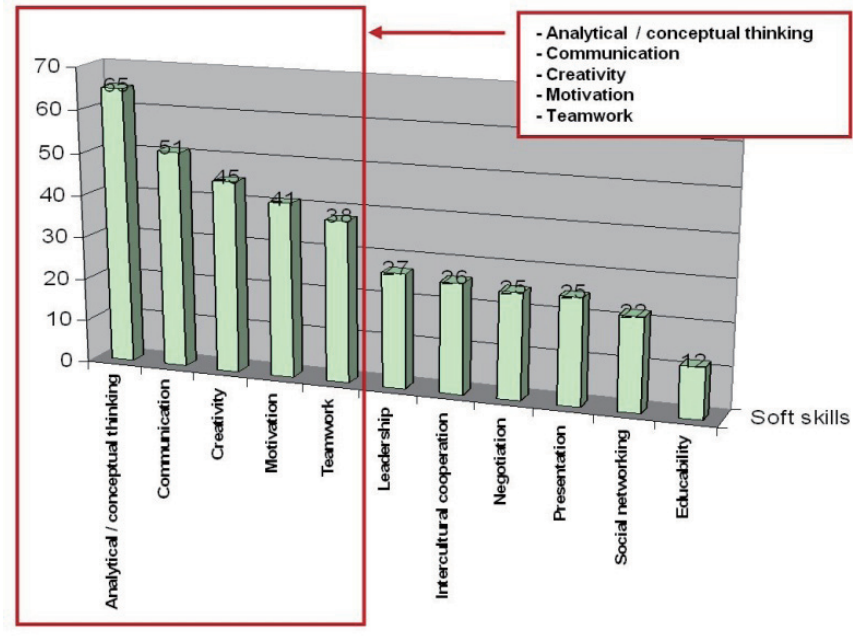

Fig. 8. Importance of soft skills (ISU survey, Doule ${ }^{5)}$ ).

ISU's educational principle, 3I (International, Interdisciplinary and Intercultural), is best fit for acquiring these skills. Students in various backgrounds are from more than 20 countries and faculty/lecturer distribution is equally diversified. The curriculum is very interdisciplinary, covering fields ranging from science/technology to business/policy/law and even social sciences. Teamwork training is iteratively provided and finally practiced to produce Team Projects of substantial quality.

As for the language communication skill, there are many different English accents and some students have to accommodate to this at the beginning. However, through the intensive team work training at the early few weeks, most students are quickly improving their linguistic communication 
skill. Besides, optional English classes are provided during the year as well as French classes.

As for international information and awareness, the following activities are useful.

- Theme Day on World Space Activities

- Discussion on international cooperation aspect in other various theme days

- Most team project needs analysis of international cooperation

There are several intercultural events in which every country is introduced by it culture and food by students of that country, though every day life with class mates is itself intercultural experience.

\section{Benefits for Japanese Students}

Japanese participation in SSP and MSS/MSM is shown in Fig. 9.

\section{SSP $\square$ MSS + MSM}

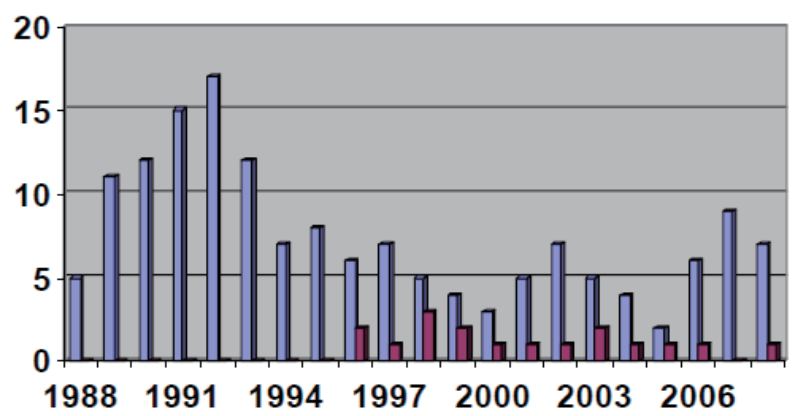

Fig. 9. Japanese participants in SSP and MSS/MSM.

Most of the Japanese participants are coming to the SSP program. This nine weeks short program seems easy to be compromised in the Japanese master course, whereas ISU's one year master program is considered more difficult to be taken in the Japanese master course sequence. Japanese industry and individual participation in ISU master course is therefore recently very modest. This situation is regrettable when considering potential benefits of MSS/MSS for Japanese participants.

The perceived benefits of MSS/MSM are,

1) The number of students in MSS/MSM is considerably smaller (near 50) than SSP, thus more intense 3I interaction can be realized.

2) A one year course provides many opportunities to closely interact with colleague students and faculty particularly thorough extensive TP activities.

Vice versa, the participation of Japanese students also increases ISU's 3I education quality and benefit to other country's participants. In the following sections, benefits of participation and possible participation arrangements are discussed with regard to several potential Japanese candidate categories for ISU

\subsection{Master course student}

Large portion of Japanese participants in the SSP Program are graduate students. The major merits of their participation are,

1) Two months term during summer holidays interferes very little with their master course program

2) Large amount of 3I experiences during this relatively short time study program

3) Some Universities provide substantial scholarship support in cooperation with ISU.

On the other hand, participation to the ISU Master programmes requests one year absence from Japan thus makes the Japanese student more reluctant to MSS/MSM than SSP participation, even if one full year of 3I education would bring them undoubtedly much greater international expertise.

There seem to be three possible forms for Japanese students to participate ISU's MSS/MSM programmes, as follows.

\section{a) Directly entering ISU after graduation of Japanese university}

In this case, recognition of ISU graduation would be important. ISU has agreements with some neighboring universities like Strasbourg University, Moscow Aviation Institute and Stuttgart University to be eligible to enter their $\mathrm{PhD}$ course. Other universities, including Japanese ones, will consider the eligibility for $\mathrm{PhD}$ candidate on a case by case basis. This might be a serious concern for Japanese students, together with the academic year deference. Another concern would be recognition at the recruitment screening by companies, particularly in Japan. Admittedly a one year master course is not popular in Japan but experiences at such a unique university would help future careers in the long run and eventually also would be of benefit for the companies involved in international business.

\section{b) Taking one year leave from a Japanese university}

In this case, there seems to be little problem about academic procedures and students can acquire powerful 3I expertise in addition to their Japanese graduate study. Although one year delay of master graduation might be felt as a quite a demerit in Japan, recent diversification and international environment of space industry would appreciate the unique education experience at ISU and strongly compensate this.

\section{c) Inclusion of ISU course as a part of Japanese master course}

This form seems the most promising to most Japanese students as it requires no delay in graduation. This is formally possible with a university which has agreement on student exchange. Unfortunately there is no such an agreement so far between ISU and Japanese Universities. However, there seems to be possibilities of (bilateral) equivalence recognition based on the specificities of the relevant university. In order to realize this type of participation, the following preparations and steps would have to be taken. 
- Intention of participation in ISU must be discussed as early as possible (even before the entrance to Japanese university) with the relevant advisor at the university in Japan.

- The ISU curriculum would have to be appropriately positioned in the student's master program in Japan. To facilitate this, ISU's Personal Assignment, Team Project and Individual Internship Project could be coordinated with the student's master theme at the Japanese university.

- Search for appropriate scholarship must be also started early if necessary.

- If the student wants to get employed just after graduation of the Japanese university, he might have to come back to Japan to take an interview with the company that he hopes to enter. This is based on the Japanese current employment system for new graduates.

As discussed above, there are good possibility and opportunity for Japanese graduate students to enter ISU master course. This kind of student interaction with ISU would help internationalization of Japanese space education and, eventually. of the space industry.

As an additional advantage, this could lead to a dual degree for the student (from both universities) increasing the attraction of such scheme. For these reasons, this approach looks the most promising one.

\subsection{Doctoral student}

There are very few cases of $\mathrm{PhD}$ candidate who have come to ISU from Japan, in contrast with other countries. Those students recognized that the ISU education was an essential part of their professional career and an asset for their thesis. Combination of doctoral level education and broad interdisciplinary expertise in addition to multi-international activities would create ideal profiles for future space activities. Evidently, also this would require good preliminary coordination between both institutions to optimize the schedule.

\subsection{Personnel of space industry}

Many companies (including space agency) have their own education programs and overseas-study allocation systems. Selection of the host institution seems to be mostly based on the applicant's proposal which tends to lean to traditional professional institutions. However, in the rapidly changing and diversified space industry, interdisciplinary and multi-national thinking in every segment of the company is very important to cope with ongoing international cooperation and competition. In this sense, space companies are highly recommended to send their personnel into very active multidisciplinary and international education environment like ISU.

The aforementioned Executive MBA takes a special place in this context. Referring to the previous ISU survey, there seems to be an increasing demand in many segments of the space sector for engineers and scientists with additional management training. Fig. 10 illustrates this request on the basis of the needs in the European space sector in terms of hard skills requested. There is no reason to believe that, with increased commercialization in the sector, such effect will increasingly manifest itself in the Japanese space sector as well.

The ISU Executive MBA program would be a possibility for the Japanese space sector to send hi-potential engineers and scientists, earmarked to operate in international markets or projects, at the same time to acquire this experience and to continue their professional activities in Japan.

\subsection{From outside the space industry}

In case of MSS/MSM program, usually more than half of the students have very little or virtually no experience in space activities. Instead, they have very high motivation and enthusiasm to enter the space industry and most of them graduate from ISU as self disciplined and broad scoped space talents. As such, for Japanese space enthusiasts now outside the space field, it would be a very good opportunity to start their career form ISU, where he/she can find many colleagues with the same motivation and other valuable resources like the world wide ISU community network he/she can access directly.

\section{Employment of ISU Graduates}

Recently many ISU students are willing to come to Japan for their internship. These students are welcomed at the host institute and do their best to contribute to the research activities there. Moreover, they are very much appreciated for their impressive 3I disciplines that affect the surrounding work place. This means that their inclusion in the workforce in Japan would promote international and intercultural awareness which would be an asset to vitalize the Japanese space sector in an international context. In addition, some ISU graduates have taken $\mathrm{PhD}$ course in Japanese universities and they are contributing in a similar way. On the other hand, for the ISU graduates, it is very difficult to be employed by Japanese companies. This is mainly or formally because of the language barrier for the newly graduates, who are required to have Japanese language capability. Comparing with the US and European space industries (where similar language barriers exist but are accommodated), Japanese internationalization seems to fall behind and this could be one of the reasons of a lack of international presence of the Japanese industry. Moreover, if this situation will not be remedied, the competitive future of the Japanese space industry might get at stake. This seems to suggest that the importance of international employment procedures should be more seriously considered in Japan. ISU alumni can provide the best opportunities for this purpose, based upon their intercultural training. 


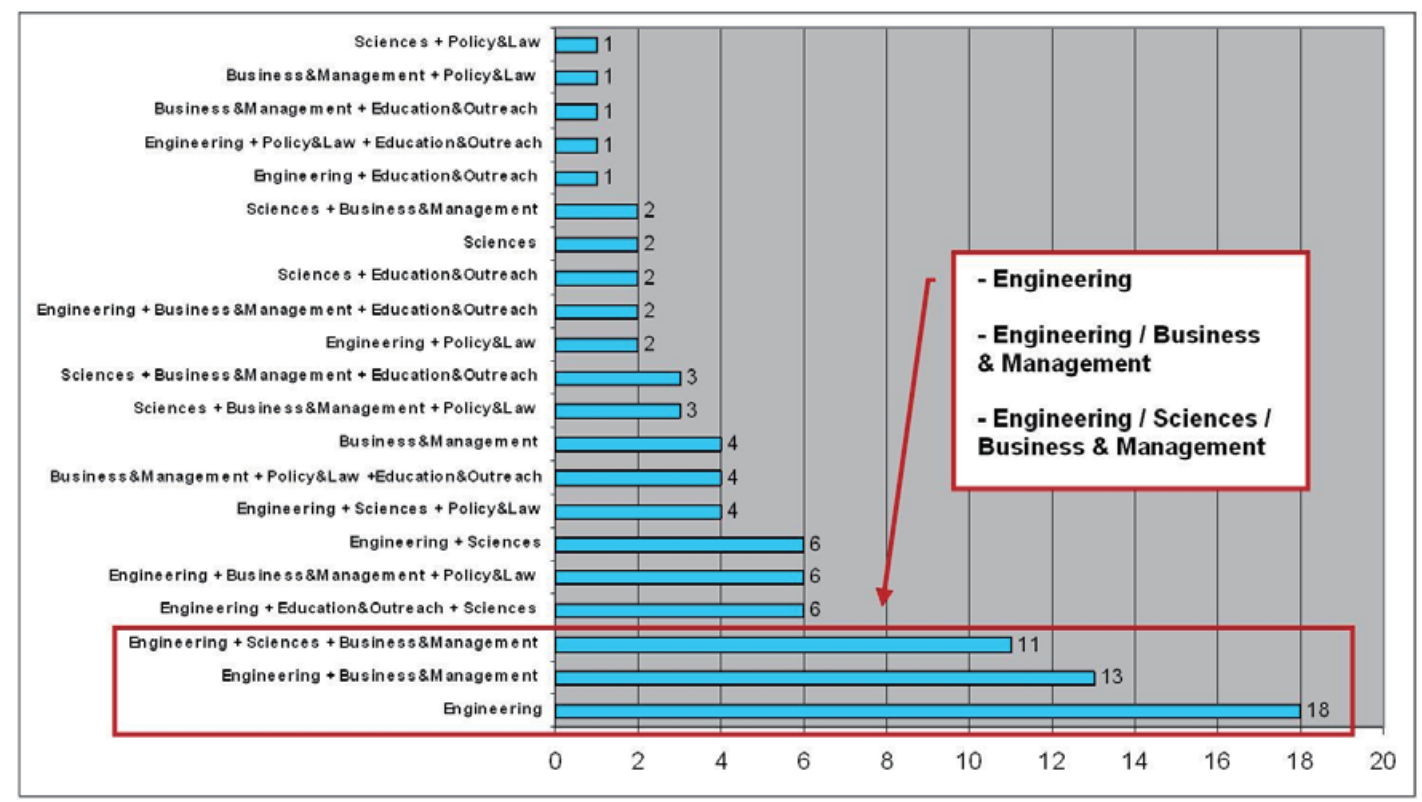

Fig. 10. Hard skill requirements (source: ISU survey, Doule ${ }^{5)}$ ).

\section{Concluding Remarks}

This paper described the current ISU educational activities and its international contribution to the space industry in general. In particular, the relationship between Japan and ISU is focused upon. The effectiveness of ISU's 3I concept has proven to be most useful for Japanese space education and has the potential to strongly contribute to internationalization of the Japanese space sector. Lastly some suggestions and considerations to promote this contribution are presented. Establishing of a dual degree at master level, based upon the agreement between ISU and a Japanese university is one viable option, whereas participation in the newly established Executive MBA for mid-level staff of the space sector seems another potential possibility.

\section{References}

1) Morino, Y. and Kodama, F.: An Analysis on Space commercialization in Japan, IAA-90-614, Dresden, 1990.

2) Ito, T. and Peeters W.: Space Education at ISU and interaction with Japan, ISTS 2005-u-15, Hamamatsu, 2005.

3) Morino, Y. and Peeters, W.: Keeping up with the Future: Preparing Leadership Talent for the Evolving Space Sector, ISTS 2008-u-5, Tsukuba, 2008.

4) ISU Home Page. http://www.isunet.edu/

5) Doule, O. and Peeters, W.: Study on the HR needs in the space sector, Paper presented at the EURISY Workshop, Prague, 2009. 